\title{
Pharmacological treatment of asthma in a cohort of adults during a 20 -year period: results from the European Community Respiratory Health Survey I, II and III
}

Christer Janson ${ }^{1,2}$, Simone Accordini ${ }^{3}$, Lucia Cazzoletti ${ }^{3}$, Isa Cerveri ${ }^{4}$, Sebastien Chanoine ${ }^{5,6}$, Angelo Corsico ${ }^{4}$, Diogenes Seraphim Ferreira ${ }^{7,8}$, Judith Garcia-Aymerich $\mathbb{0}^{9,10,11}$, David Gislason ${ }^{12}$, Rune Nielsen ${ }^{13,14}$, Ane Johannessen ${ }^{15}$, Rain Jogi ${ }^{16}$, Andrei Malinovschi ${ }^{17}$, Jesús Martinez-Moratalla Rovira ${ }^{18,19}$, Alessandro Marcon $\mathbb{0}^{3}$, Isabelle Pin ${ }^{5,20}$, Jennifer Quint ${ }^{2}$, Valerie Siroux ${ }^{5}$, Enrique Almar ${ }^{19,21,+}$, Valeria Bellisario ${ }^{22}$, Karl A. Franklin²3, José A. Gullón (1024, Mathias Holm²5, Joachim Heinrich ${ }^{26,27,28}$, Dennis Nowak ${ }^{26,29}$, José Luis'Sánchez-Ramos (10), Joost J. Weyler ${ }^{31}$ and Deborah Jarvis ${ }^{2}$

ABSTRACT Asthma often remains uncontrolled, despite the fact that the pharmacological treatment has undergone large changes. We studied changes in the treatment of asthma over a 20 -year period and identified factors associated with the regular use of inhaled corticosteroid (ICS) treatment.

Changes in the use of medication were determined in 4617 randomly selected subjects, while changes in adults with persistent asthma were analysed in 369 participants. The study compares data from three surveys in 24 centres in 11 countries.

The use of ICSs increased from $1.7 \%$ to $5.9 \%$ in the general population and the regular use of ICSs increased from $19 \%$ to $34 \%$ among persistent asthmatic subjects. The proportion of asthmatic subjects reporting asthma attacks in the last 12 months decreased, while the proportion that had seen a doctor in the last 12 months remained unchanged (42\%). Subjects with asthma who had experienced attacks or had seen a doctor were more likely to use ICSs on a regular basis.

Although ICS use has increased, only one-third of subjects with persistent asthma take ICSs on a regular basis. Less than half had seen a doctor during the last year. This indicates that underuse of ICSs and lack of regular healthcare contacts remains a problem in the management of asthma.

@ERSpublications

Despite increased ICS use, only $34 \%$ of subjects with persistent asthma take ICSs on a regular basis; $<\mathbf{5 0 \%}$ have seen a doctor in the last year. Underuse of ICSs and lack of regular healthcare contacts remains a problem in asthma. http://ow.ly/GUZ630mZkVN

Cite this article as: Janson C, Accordini S, Cazzoletti L, et al. Pharmacological treatment of asthma in a cohort of adults during a 20 -year period: results from the European Community Respiratory Health Survey I, II and III. ERJ Open Res 2019; 5: 00073-2018 [https://doi.org/10.1183/ 23120541.00073-2018]. 


\section{Introduction}

The pharmacological treatment of asthma has undergone large changes during the last two decades with new treatment options such as long-acting $\beta_{2}$-agonists (LABAs), leukotriene antagonist (LTRAs), fixed combinations of inhaled corticosteroids (ICSs) and LABAs (ICS+LABA), long-acting muscarinic receptor antagonists (LAMAs), anti-IgE, and anti-interleukin (IL)-5 therapies. International guidelines have been available since the 1990s and are continuously updated with regular use of ICSs as the cornerstone of first-line treatment of asthma [1]. Despite this there are reports showing that asthma remains uncontrolled in a large proportion of patients [2-4], still has a large effect on quality of life $[5,6]$, influences patients' sleep $[7,8]$ and causes a large economic burden for society $[9,10]$.

The European Community Respiratory Health Survey (ECRHS) is a unique study where participants from the general population in a large number of countries have been surveyed 3 times over a 20-year period $[11,12]$. At the first ECRHS survey (ECRHS I), large differences were found regarding the prevalence of asthma therapy, with an 8-fold difference in the use of ICSs among countries [13]. In the second survey (ECRHS II) there was an increase in the use of ICSs, but despite this only $17 \%$ of participants with asthma were using ICSs on a daily basis [14]. Analyses from the first two time-points showed that females with asthma were more likely and smokers with asthma less likely to use ICSs than males and nonsmokers, respectively $[14,15]$. A surprisingly low use of ICSs on a daily basis in asthmatic subjects has also been found in other studies $[4,16]$. Change in medication is influenced by longitudinal change in the prevalence of asthma and asthma symptoms. Longitudinal studies of asthma and asthma symptoms in adults have shown diverging results, with an increase in self-reported asthma and asthma symptoms with age in an English and a Canadian study [17, 18], and a decrease in the prevalence of asthma symptoms in a German study [19]. There are, however, very few studies of longitudinal change in the pharmacological treatment of asthma and such studies are needed in order to optimise the therapeutic management of asthma at the population level.

The third survey of the ECRHS (ECRHS III) was completed between 2011 and 2014. An analysis of data from a short postal questionnaire showed an increase in the use of asthma medication [20]. The aim of the present study was to undertake a more detailed investigation of changes in the pharmacological treatment of asthma over a 20 -year period and to investigate factors associated with the regular use of ICSs.

\section{Methods}

\section{Population}

The designs of ECRHS I and II have been described in detail [21, 22]. In ECRHS I, each participant was sent a brief questionnaire (stage 1) and from those who responded, a random population-based sample

Affiliations: ${ }^{1}$ Respiratory, Allergy and Sleep Research, Dept of Medical Sciences, Uppsala University, Uppsala, Sweden. ${ }^{2}$ Population Health and Occupational Disease, National Heart and Lung Institute, Imperial College London, London, UK. ${ }^{3}$ Unit of Epidemiology and Medical Statistics, Dept of Diagnostics and Public Health, University of Verona, Verona, Italy. ${ }^{4}$ Division of Respiratory Diseases, IRCCS, Policlinico San Matteo Foundation, Dept of Internal Medicine and Therapeutics, University of Pavia, Pavia, Italy. ${ }^{5}$ Team of Environmental Epidemiology Applied to Reproduction and Respiratory Health, Institute for Advanced Biosciences, Inserm, Université Grenoble Alpes, Grenoble, France. ${ }^{6}$ Pôle Pharmacie, CHU Grenoble Alpes, Grenoble, France. ${ }^{7}$ School of Public Health and Preventive Medicine, Monash University, Melbourne, Australia. ${ }^{8}$ Alergia e Imunologia, Complexo Hospital de Clinicas, Universidade Federal do Parana, Curitiba, Brazil. ${ }^{9}$ ISGlobal, Centre for Research in Environmental Epidemiology (CREAL), Barcelona, Spain. ${ }^{10}$ Universitat Pompeu Fabra (UPF), Barcelona, Spain. ${ }^{11}$ CIBER Epidemiología y Salud Pública (CIBERESP), Barcelona, Spain. ${ }^{12}$ Dept of Respiratory Medicine and Sleep, Landspitali, Reykjavik, Iceland. ${ }^{13}$ Dept of Thoracic Medicine, Haukeland University Hospital, Bergen, Norway. ${ }^{14}$ Dept of Clinical Science, University of Bergen, Bergen, Norway. ${ }^{15}$ Centre for International Health, Dept of Global Public Health and Primary Care, University of Bergen, Bergen, Norway. ${ }^{16}$ Lung Clinic, Tartu University Hospital, Tartu, Estonia. ${ }^{17}$ Clinical Physiology, Dept of Medical Sciences, Uppsala University, Uppsala, Sweden. ${ }^{18}$ Servicio de Neumología, Complejo Hospitalario Universitario, Albacete, Spain. ${ }^{19}$ Facultad de Medicina Albacete, University of Castilla-La Mancha, Ciudad Real, Spain. ${ }^{20}$ Dept of Paediatrics, CHU Grenoble Alpes, Grenoble, France. ${ }^{21}$ Service of the Health Delegation of Albacete, Albacete, Spain. ${ }^{22}$ Dept of Public Health and Paediatrics, University of Turin, Turin, Italy. ${ }^{23}$ Dept of Surgical and Perioperative Sciences, Surgery, Umeå University, Umeå, Sweden. ${ }^{24}$ Dept of Pneumology, Universitary Hospital San Agustín, Avilés, Spain. ${ }^{25}$ Dept of Occupational and Environmental Medicine, University of Gothenburg, Gothenburg, Sweden. ${ }^{26}$ Institute and Clinic for Occupational, Social and Environmental Medicine, University Hospital, LMU Munich, Comprehensive Pneumology Center (CPC) Munich, Member German Center for Lung Research (DZL), Munich, Germany. ${ }^{27}$ Institute of Epidemiology, Helmholtz Zentrum München - German Research Centre for Environmental Health, Neuherberg, Germany. ${ }^{28}$ Allergy and Lung Health Unit, Melbourne School of Population and Global Health, The University of Melbourne, Melbourne, Australia. ${ }^{29}$ Comprehensive Pneumology Center (CPC) Munich, Member German Center for Lung Research (DZL), Munich, Germany. ${ }^{30}$ Dept of Nursing, University of Huelva, Huelva, Spain. ${ }^{31}$ StatUA Statistics Center, University of Antwerp, Antwerp, Belgium.

Correspondence: Christer Janson, Respiratory, Allergy and Sleep Research, Dept of Medical Sciences, Uppsala University, Akademiska Sjukhuset, Uppsala 751 85, Sweden. E-mail: christer.jansonamedsci.uu.se 
was selected to undergo a more detailed clinical examination. In addition, a "symptomatic sample", reporting been woken by an attack of shortness of breath, asthma attacks or using asthma medication in stage 1, was also invited to the same clinical examination. This examination included spirometry, allergy testing and a structured interview. In ECRHS II, subjects who had participated in the clinical phase of ECRHS I were invited to participate in the follow-up. The clinical phase of ECRHS I and II was performed during 1991-1994 and 1998-2002, respectively. ECRHS III is the second follow-up and was performed from February 2011 to January 2014 [23]. The numbers of participants in the various parts of ECRHS I-III are presented in figure 1.

Only participants from the random sample were included when describing change in the prevalence of use of medication and geographical difference in the general population. The participants who had originally been selected as part of the random or the symptomatic sample were included when analysing medication in subjects with persistent asthma.

\section{Centres and countries}

This investigation included 24 centres from 11 countries: Iceland (Reykjavik), Norway (Bergen), Sweden (Gothenburg, Umeå and Uppsala), Estonia (Tartu), Germany (Erfurt and Hamburg), UK (Ipswich and Norwich), Belgium (Antwerp), France (Bordeaux, Grenoble, Montpellier and Paris), Spain (Albacete, Barcelona, Galdakao, Huelva and Oviedo), Italy (Pavia, Torino and Verona) and Australia (Melbourne).

\section{Questionnaire}

The subjects underwent a structured interview asking for detailed information on respiratory symptoms, asthma and asthma therapy. Pictures, samples or lists of different asthma medications were shown to facilitate a correct answer to the therapy questions.

\section{Definition of asthma-related variables}

Physician-diagnosed asthma: a positive answer to the questions "Have you ever had asthma?" and "Was this confirmed by a doctor?".

Asthma-related symptoms in the last 12 months: reported having had wheeze, nocturnal chest tightness or attacks of breathlessness following activity, at rest or at night during the last 12 months.

Current asthma: having physician-diagnosed asthma and having had at least one of the following criteria: asthma-related symptoms, attacks of asthma in the last 12 months or reported current use of any medicines for asthma.

Persistent asthma: having current asthma at all three surveys.

The participants were also asked whether they had asthma attacks within the last 12 months and if "yes", the number of attacks.

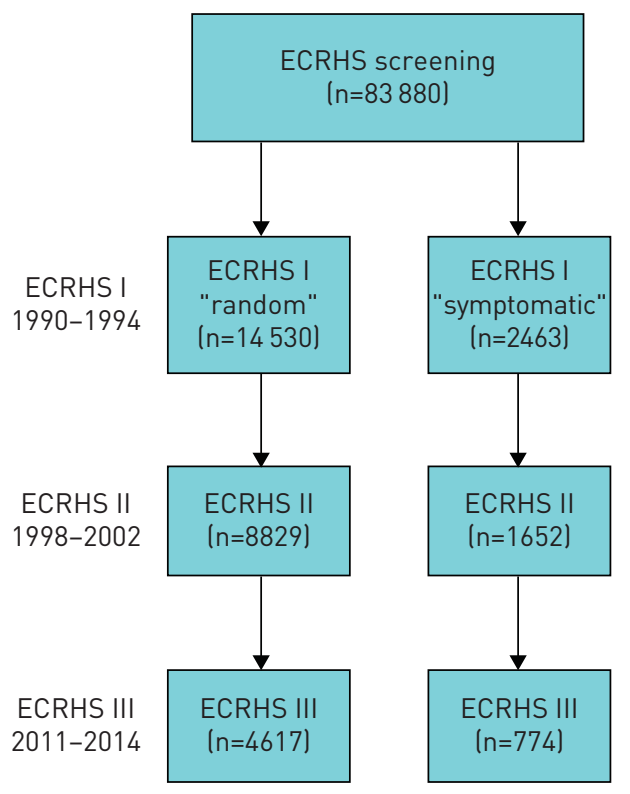


Medications for asthma

Participants were considered to be taking medication for asthma if they reported having used any of the following drugs for their breathing in the 12 months preceding each survey: 1) inhaled asthma medications (short-acting $\beta_{2}$-agonists (SABAs), LABAs, short-acting muscarinic receptor antagonists, LAMAs and ICSs), 2) oral asthma medications ( $\beta_{2}$-agonists, theophylline, LTRAs and oral corticosteroids (OCSs)) and 3 ) injections for the treatment of allergy (including omalizumab). Patients who used fixed combinations of ICS+LABA were considered to be using both drugs. Patients that reported having used ICSs "continuously" in the last 3 months before each survey were defined as regular users of ICSs.

\section{Healthcare utilisation}

The participants were asked whether they had spent a night in hospital and whether they had been seen by a doctor because of breathing problems in the 12 months preceding each survey.

\section{Smoking, chronic obstructive pulmonary disease, educational level and body mass index}

Current smoker was defined by answering yes to the two questions "Have you ever smoked for as long as a year?" and "Do you now smoke, as of 1 month ago?". In ECRHS III the participants were asked whether a doctor ever told them that they have chronic obstructive pulmonary disease (COPD). Information on educational level was collected in ECRHS I and a low education level was defined as having completed full-time education before the age of 16 years [14]. Body mass index (BMI) was calculated from height and weight recorded in all three surveys.

\section{Ethics approval}

Local ethics committees at each centre approved the study protocols. All participants provided written informed consent.

\section{Statistics}

All statistical analyses were conducted using Stata version 14 (StataCorp, College Station, TX, USA). Absolute net changes in medication, asthma attacks and healthcare utilisation between the surveys were estimated using population-averaged, generalised estimating equations for a binomial outcome with identity link, with participants identified as the clustering factor and the number of the survey as an independent variable. Results were expressed as net percentage change between surveys. The Wald test was used to examine differences in change of prevalence by survey. Estimated changes in treatments by country were examined for heterogeneity and combined using random effects meta-analyses.

The Chi-squared test was used when comparing the prevalence of medication between countries in cross-sectional analyses. Spearman's correlation test was used when analysing the ecological association between the prevalence of current asthma and the prevalence of the use of medication for asthma.

We assessed the influence of several personal and asthma characteristics on the regular use of ICS treatment among subjects with persistent asthma. The associations were estimated using mixed effects logistic regressions with the participant as the clustering unit to account for the repeated measurements. The factors assessed were chosen based on previous experience [14], and included age, sex, BMI, smoking, educational level, doctor visits, hospitalisations, asthma attacks, survey and country. Only variables with a p-value $<0.1$ in the unadjusted analyses were included in the final model.

\section{Results}

Use of medications for asthma in the random population sample

The random sample included 4617 subjects $(52.1 \%$ female) that were seen at all three surveys. The mean \pm SD age at ECRHS I was $34.4 \pm 7.1$ years and the mean follow-up was 20.1 years. Those who participated in all three surveys were less likely to be smokers (32.7\% versus $39.8 \%$ ), were slightly older (mean \pm SD age $34.4 \pm 7.1$ versus $33.2 \pm 7.2$ years; $\mathrm{p}<0.0001)$ and had used SABAs more often $(4.8 \%$ versus $3.6 \% ; \mathrm{p}=0.003$ ) at ECRHS I than those that only participated in the first survey. No significant difference was found in sex and BMI distribution or use of ICSs between those that participated in all three surveys and those that only participated in the first survey (data not shown).

The prevalence of use of medication for asthma had almost doubled from 5.2\% to $9.9 \%$ between ECRHS I and III (table 1). A significant increase was found for all inhaled compounds as well as LTRAs and OCSs, while a significant decrease was found for theophylline. Changes in the use of ICSs between ECRHS I and III by country are presented in figure 2. A significant increase was found in most countries. There was significant heterogeneity between countries.

In the random sample, $43(0.9 \%)$ participants reported that they had a diagnosis of COPD. Excluding these subjects had only a marginal effect on the prevalence of use of pharmacological treatment. As an 


\section{TABLE 1 Use of medication during the last 12 months in the random sample}

\begin{tabular}{lcccc} 
& ECRHS I & ECRHS II & ECRHS III & Change in prevalence \\
\hline $\begin{array}{l}\text { Inhaled SABAs } \\
\text { Inhaled LABAs }\end{array}$ & 3.6 & 5.7 & 6.2 & $2.7(2.0-3.4)$ \\
ICSs & & 1.2 & 4.2 & $3.0(2.4-3.6)$ \\
ICS+LABA & 1.7 & 4.0 & 5.9 & $4.2(3.5-4.9)$ \\
Inhaled anticholinergics & & 0.9 & 3.8 & $2.9(2.4-3.5)$ \\
Theophylline & 0.2 & 0.2 & 0.5 & $0.3(0.07-5.1)$ \\
Oral $\boldsymbol{\beta}_{2}$-agonists & 0.7 & 0.2 & 0.1 & $-0.6(-0.9--0.4)$ \\
LTRAs & 0.4 & 0.3 & 0 & $-0.4^{+}$ \\
OCSs & & 0.2 & 0.6 & $0.4(0.2-0.7)$ \\
Any medication for asthma & 0.6 & 1.1 & 1.0 & $0.4(0.1-0.8)$ \\
& 5.2 & 8.0 & 9.9 & $4.8(3.9-5.6)$
\end{tabular}

Data are presented as \%, and change between European Community Respiratory Health Survey (ECRHS) I and III in \% (95\% CI), or in case of absence of information from ECRHS I, change between ECRHS II and ECRHS III in \% (95\% CI). SABA: short-acting $\beta_{2}$-agonist; LABA: long-acting $\beta_{2}$-agonist; ICS: inhaled corticosteroid; LTRA: leukotriene receptor antagonist; OCS: oral corticosteroid. \#: $n=4617$; " : as a single inhaler or in combination; ${ }^{+}$: not possible to calculate $95 \%$ confidence interval.

example, the prevalence of use of ICSs decreased from $5.9 \%$ to $5.5 \%$ and the corresponding values for SABAs were from $6.2 \%$ to $5.9 \%$.

The highest prevalence of current asthma and medication use for asthma in ECRHS III was found in Australia and the lowest in Belgium (table 2). There were statistically significant differences between the countries in the use of SABAs and LABAs, but not in the use of ICSs. There was a strong statistical ecological association between the prevalence of current asthma and the prevalence of use of any medication for asthma, whereas no significant association was found between the prevalence of asthma and the prevalence of ICS use (figure 3).

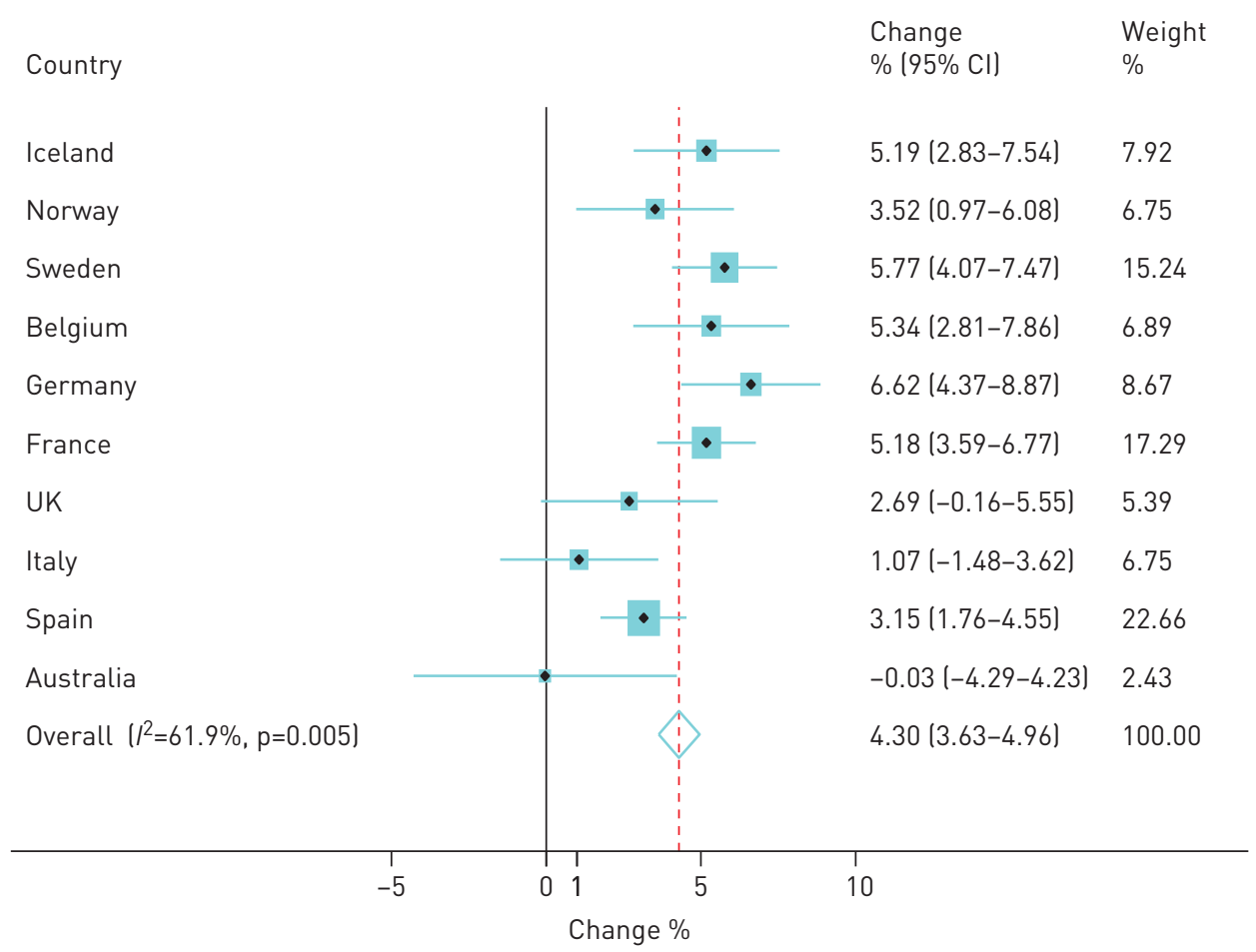

FIGURE 2 Change in the use of inhaled corticosteroids las a single inhaler or in combination; any use in the last 12 months) in the random sample between European Community Respiratory Health Survey (ECRHS) I and III analysed by country and combined in a meta-analysis. Analysis was not possible for Estonia due to the limited number of participants. The area of each square is proportional to the reciprocal of the variance of the estimate for the country. The combined random effects estimate is shown by the dashed line; the width of the diamond is the $95 \%$ confidence interval. 
TABLE 2 Prevalence of current asthma and use of medication for asthma in the random sample at European Community Respiratory Health Survey III per participating country

\begin{tabular}{lcccccc} 
& Subjects & Current asthma & SABA & LABA $^{\#}$ & ICS $^{\#}$ & Any medication \\
\hline Iceland & 347 & 12.4 & 8.4 & 5.7 & 5.4 & 11.2 \\
Norway & 330 & 12.2 & 8.0 & 5.9 & 5.9 & 12.1 \\
Sweden & 717 & 9.8 & 7.8 & 4.0 & 6.7 & 10.7 \\
Estonia & 105 & 7.6 & 2.9 & 4.8 & 7.6 & 8.6 \\
Belgium & 286 & 3.5 & 1.5 & 3.6 & 4.9 & 5.6 \\
Germany & 377 & 11.4 & 3.6 & 4.4 & 8.0 & 8.8 \\
France & 889 & 12.3 & 7.1 & 4.7 & 6.8 & 12.5 \\
UK & 249 & 13.3 & 12.4 & 2.0 & 3.6 & 12.8 \\
Italy & 226 & 9.7 & 4.0 & 0 & 4.0 & 6.6 \\
Spain & 872 & 7.9 & 3.7 & 3.6 & 4.6 & 6.7 \\
Australia & 219 & 16.9 & 10.7 & 8.0 & 8.5 & 15.5 \\
p-value & & $<0.0001$ & $<0.0001$ & 0.003 & 0.13 & $<0.0001$ \\
\hline
\end{tabular}

Data are presented as $n$, unless otherwise stated. SABA: short-acting $\beta_{2}$-agonist; LABA: long-acting $\beta_{2}$-agonist; ICS: inhaled corticosteroid. ${ }^{\#}$ : as single inhalers or in combination.

\section{Treatment in subjects with persistent asthma}

The number of participants with current asthma in the combined random and symptomatic sample $(\mathrm{n}=5391)$ was 516 (9.6\%) in ECRHS I, 720 (13.4\%) in ECRHS II and 856 (15.9\%) in ECRHS III. Of these, 369 had persistent asthma. Approximately three out of four subjects with persistent asthma reported having used medication for asthma in the last 12 months in all three surveys, but there was a significant increase in the use of LABAs, ICSs and LTRAs, and a decreased use of SABAs and theophylline (table 3).

Of the participants with persistent asthma, 17 (4.6\%) had physician-diagnosed COPD. Excluding these participants had only a minor effect on the prevalence of pharmacological treatment. The prevalence of ICS use in ECRHS III decreased from $49.1 \%$ to $48.5 \%$ and the corresponding values for SABAs were from $58.0 \%$ to $57.4 \%$.

The proportion of adults with asthma who reported regular use of ICSs increased (table 3). This increase was from $21.5 \%$ to $41.8 \%$ when excluding asthmatic subjects without self-reported asthma attacks. Changes in regular use of ICSs between ECRHS I and III by country are presented in figure 4. No significant heterogeneity between countries was found.

Asthma attacks decreased throughout the study, whereas hospitalisations and the proportion of participants who reported having seen at doctor for their breathing problem in the last 12 months remained stable (table 3).
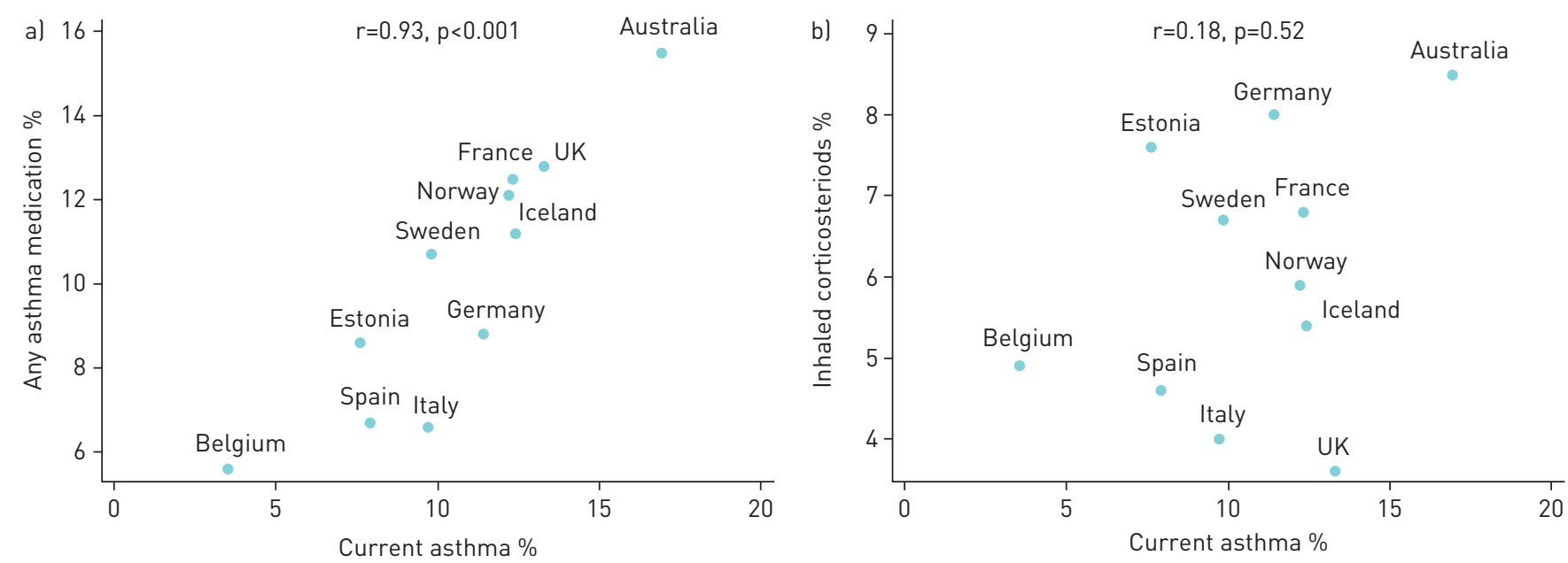

FIGURE 3 Ecological analysis of the association between prevalence of current asthma and the use of mediation for asthma in each country: al any asthma medication and b) inhaled corticosteroids. 
TABLE 3 Use of medication, asthma attacks and healthcare utilisation during the last 12 months in subjects with persistent asthma $^{\#}$

ECRHS I

\section{Inhaled SABA}

Inhaled LABAs?

ICSs "

ICSs used daily in the last 3 months

ICS+LABA

Inhaled anticholinergics

Theophylline

Oral $\boldsymbol{\beta}_{2}$-agonists

LTRAs

OCSs

Any medication for asthma

Hospitalisations

At least one asthma attack in the last 12 months

Three or more asthma attacks in the last 12 months

Doctor visit for breathing problems in the last 12 months

$\begin{array}{ccc}68.6 & 67.5 & 58.0 \\ & 14.8 & 40.4 \\ 31.4 & 46.2 & 49.1 \\ 18.8 & 26.3 & 32.8 \\ & 12.7 & 36.4 \\ 2.6 & 2.3 & 3.7 \\ 13.0 & 2.9 & 0.3 \\ 7.5 & 1.7 & 0 \\ & 3.3 & 7.1 \\ 8.8 & 9.1 & 6.7 \\ 72.9 & 76.9 & 73.9 \\ 2.2 & 1.5 & 1.2 \\ 68.8 & 51.0 & 40.9 \\ 46.5 & 35.8 & 25.8 \\ 41.7 & 34.3 & 42.3\end{array}$

Change in prevalence

$-10.1(-15.5--4.7)$

$25.3(19.5-31.1)$

$17.2(11.6-22.9)$

$13.5(8.6-18.3)$

$23.5(17.9-29.0)$

$1.0(-1.5-3.4)$

$-12.5(-15.9-9.1)$

$-7.5^{+}$

$3.7(0.07-6.7)$

$-1.6(-5.1-1.9)$

$1.2(3.2-5.7)$

$-1.1(-3.0-0.8)$

$-27.9(-33.7--22.1)$

$-20.8(-26.5--15.0)$

$0.6(-5.7-6.9)$

Data are presented as \% or \% (95\% CI). ECRHS: European Community Respiratory Health Survey; SABA: short-acting $\beta_{2}$-agonist; LABA: long-acting $\beta_{2}$-agonist; ICS: inhaled corticosteroid; LTRA: leukotriene receptor antagonist; OCS: oral corticosteroid. ${ }^{\#}$ : $n=369 ;{ }^{\uparrow}:$ as a single inhaler or in combination; ${ }^{+}$: not possible to calculate $95 \%$ confidence interval.

Variables associated with the regular use of ICSS

Using ICSs on a regular basis in the participants with persistent asthma was related to having had asthma attacks and having been seen by a doctor in the last 12 months (table 4). There was also an association of borderline statistical significance between higher age and regular use of ICSs $(p=0.06)$.

\section{Discussion}

The main finding in the present analysis was an increase in the use of medication for asthma (e.g. ICSs and LABAs) in the general population during the 20-year follow-up period. Among those with persistent

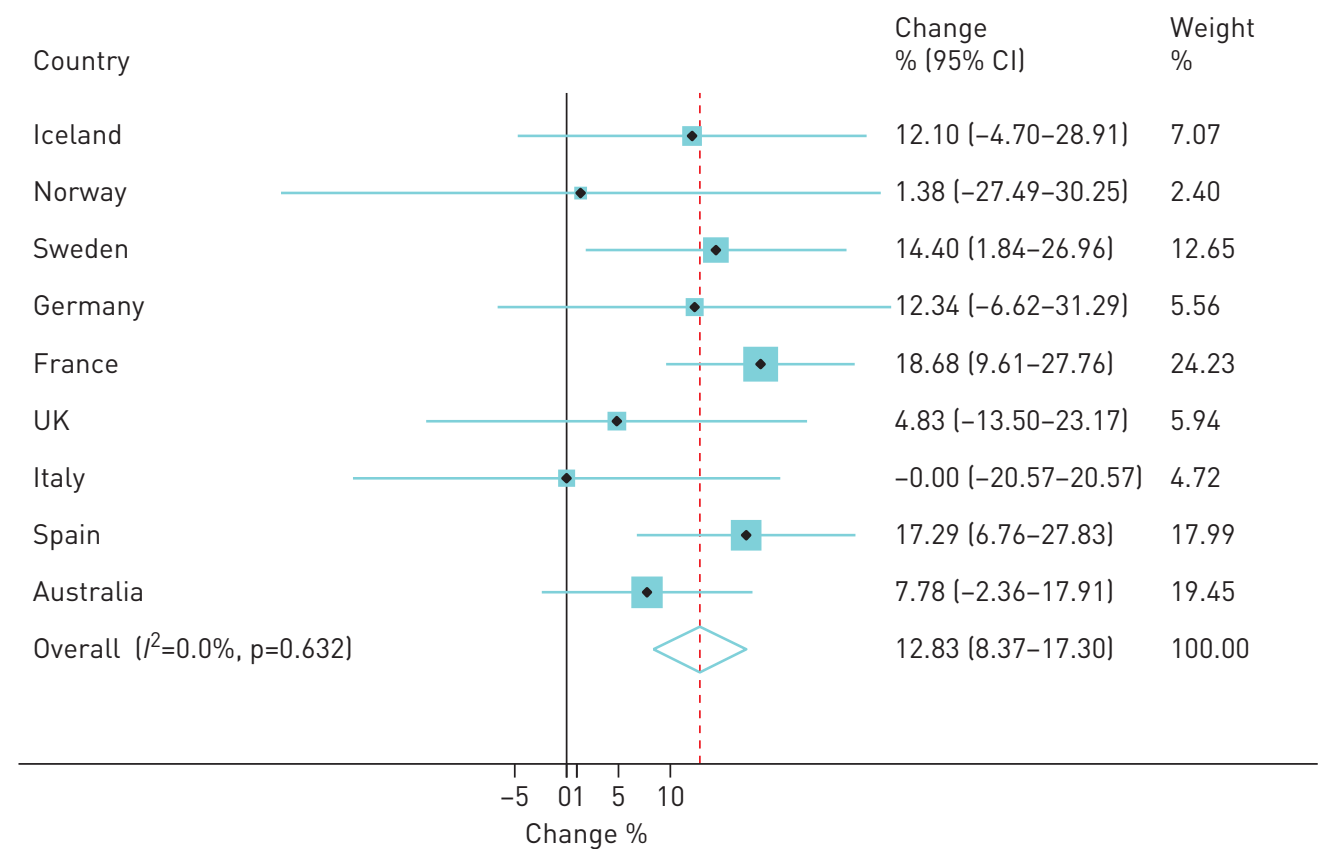

FIGURE 4 Change in the regular use of inhaled corticosteroids las a single inhaler or in combination; any use in the last 12 months) in participants with persistent asthma analysed by country and combined in a meta-analysis. Analysis was not possible for Estonia due to the limited number of participants. The area of each square is proportional to the reciprocal of the variance of the estimate for the country. The combined random effects estimate is shown by the dashed line; the width of the diamond is the $95 \%$ confidence interval. 


\begin{tabular}{|c|c|c|}
\hline & Crude OR $(95 \% \mathrm{CI})$ & Adjusted OR $(95 \% \mathrm{CI})^{\text {१ }}$ \\
\hline Female & $2.16(1.09-4.28)$ & $1.61(0.81-3.13)$ \\
\hline Age at baseline (per 10 year) & $1.59(0.97-2.61)$ & $1.61(0.98-2.64)$ \\
\hline BMI (per 5 units) & $1.69(1.20-2.38)$ & $1.23(0.87-1.75)$ \\
\hline Current smoking & $0.38(0.17-0.85)$ & $0.89(0.38-2.09)$ \\
\hline Low educational level & $1.61(0.51-5.04)$ & Not included \\
\hline Asthma attack in the last 12 months & $2.09(1.23-3.55)$ & $2.56(1.37-4.79)$ \\
\hline Doctor visit in the last 12 months & $4.27(2.51-7.27)$ & $3.58(1.96-6.55)$ \\
\hline Hospitalisation in the last 12 months & $9.76(0.63-150)$ & Not included \\
\hline
\end{tabular}

asthma there has been a reduction in asthma attacks, suggesting an improvement of asthma control. However, two-thirds of adults with persistent asthma did not take ICSs regularly, $40 \%$ reported having at least one asthma attack and less than half had seen a doctor because of their breathing problem in the last year.

In the present study a third of the participants with persistent asthma were using ICSs on a regular basis at the second follow-up. This is almost a doubling proportion compared with the first survey in 1991-1994 [13], but still a surprisingly low figure given that the regular use of ICSs is recommended in all adults with asthma except in those with infrequent asthma symptoms $[1,24]$. An increased use of ICSs over time is in accordance with data from a large Canadian registry study [25], but our findings also reflect those of the 1999 AIRE (Asthma insights and reality in Europe) study which reported low ICS use in asthma [4]. A low usage of ICSs on a daily basis was also reported in the REALISE (Recognise asthma and link to symptoms and experience) study, where over half of the participants on preventer therapy reported using this less than daily [16]. AIRE and REALISE also showed a high prevalence of uncontrolled asthma, a finding that has been replicated in several other studies $[2,3]$. A positive aspect is that we found a decrease in reported asthma attacks, which suggests an improvement in asthma control; even in the present study $40 \%$ of those with persistent asthma reported having had at least one asthma attack in the last year. This result is in accordance with a recent report from a Canadian study [26], but in contrast with some previous studies reporting that the level of asthma control is not improving over time [2, 27, 28]. One reason for this is that this is a cohort study, and we are therefore looking at both temporal and age-related changes.

Several new types of drugs have been introduced during the follow-up time of the ECRHS. LABAs are now used by two-thirds of those using ICSs in ECRHS III. The addition of LABAs to ICSs has been shown to decrease exacerbations and improve symptom control in asthmatic subjects that are not well controlled with ICSs alone [29]. However, there are also data indicating that the ICS+LABA combination is used in some patients that could be controlled with ICSs alone [30]. Treatment with LTRAs has also been shown to improve asthma control when added to ICSs in patients with uncontrolled asthma [31]. LTRAs are included in international guidelines as an alternative to LABAs [1]. Despite this we found that LTRAs had been used in less than one out of 10 of the adults with asthma in ECRHS III. The use of theophylline and oral $\beta_{2}$-agonists has almost disappeared during this 20 -year study period. Anticholinergics were used only by a small number of patients, which is expected as tiotropium was introduced in asthma guidelines in 2015 [32]. None of the participants reported using omalizumab or anti-IL-5 treatment.

At the first ECRHS survey large differences were found regarding the prevalence of use of ICSs among countries [13]. This difference is much lower now and, in fact, no longer statistically significant. This change might be related to the fact that the Global Initiative for Asthma (GINA) guidelines [1] as well as national guidelines [33] have been implemented in most countries. As in our previous analyses of ECRHS, we found the highest prevalence of current asthma and use of medication for asthma was in Australia [13]. There was a strong correlation between the prevalence of asthma and the prevalence of use of any medication for asthma in the ECRHS countries. This was, however, not the case for the prevalence of ICS use, indicating that factors other than asthma prevalence may play a role in how much ICS is used in a country. These factors may include national guidelines, different views on the risk of ICS-related side-effects and differences how the healthcare system is organised in the different countries.

Having seen a doctor for breathing problems increased the likelihood of regular ICS use. However, in the present study only $\sim 40 \%$ of the adults with asthma had seen a doctor in the last year for breathing 
problems. These results are in accordance with those from a recent study that also showed that most asthmatic subjects in Sweden lacked regular healthcare contacts [34]. The results of the present study suggest that having regular follow-ups in patients with asthma may be a way of improving treatment in asthma. This is probably related to increased adherence, as regular healthcare consultations was the strongest predictor for increased adherence between ECRHS I and II in a previous analysis [35]. An alternative way of interpreting our results is that patients with more frequent symptoms tend to use asthma drugs more frequently and require more frequent doctor visits. This interpretation is supported by the fact that the other factor that was related to regular ICS use was having had asthma attacks, which is what is to be expected as ICSs are often used to decrease the risk of further asthma attacks. In analyses of ECRHS I and II we have previously reported that current smokers with asthma were less likely to be using asthma medications [15], and to have started using ICSs between the first and second survey [14]. This was also found in the unadjusted analysis in the present study, but the association was not significant after adjusting for other variables such as doctor visits and asthma attacks. In the same way, we found that females were more likely to use ICSs than males in the unadjusted analyses $[14,15]$, but this association also became nonsignificant in the adjusted model. In the present analysis there was a borderline significant association between regular use of ICSs and higher age. This finding is in accordance with some previous studies showing a higher adherence to use of ICSs in older patients [36, 37].

The present study is unique in that we were able to follow a large population sample for 20 years. The methodology used in the three surveys was identical and this, together with the large sample size, is a major strength of the study. A weakness is that we lost a relatively large proportion of those investigated in the first survey. The nonparticipants were somewhat younger, and more likely to be smokers and to use SABAs. Another weakness is that we fully rely on self-reported data. The number of participants from each country was small and therefore the geographical variation shown in the study may not necessarily give an accurate picture of the geographical pattern in asthma treatment. As the participants are selected from the general population, most participants with asthma will have mild asthma and the study therefore gives little information on treatment with severe asthma. In the study we used self-reported asthma attacks as a proxy for asthma control. The reason for this is that the GINA definition of asthma control [1] was not available at the first survey.

In conclusion, this longitudinal survey shows that the therapeutic management of asthma has changed over time, with an increase in the use of ICSs and ICS+LABA combinations. There was also a decrease in reported asthma attacks. Despite this, only one-third of subjects with asthma were regularly using ICSs, $40 \%$ reported having at least one asthma attack and less than half had seen a doctor in the last 12 months. This indicates that underuse of ICSs and lack of regular healthcare remains a problem in the management of asthma.

The members of the ECRHS I scientific team. Coordinating Centre (London): P. Burney, S. Chinn, C. Luczynska ${ }^{\dagger}$, D. Jarvis, E. Lai. Project Management Group: P. Burney (Project Leader; UK), S. Chinn (UK), C. Luczynska ${ }^{\dagger}$ (UK), D. Jarvis (UK), P. Vermeire (Antwerp), H. Kesteloot (Leuven), J. Bousquet (Montpellier), D. Nowak (Hamburg), J. Prichard ${ }^{\dagger}$ (Dublin), R. de Marco ${ }^{\dagger}$ (Verona), B. Rijcken (Groningen), J.M. Anto (Barcelona), J. Sunyer (Barcelona), J. Alves (Oporto), G. Boman (Uppsala), N. Nielsen (Copenhagen), P. Paoletti (Pisa). Participating Centres: Australia: Melbourne (M. Abramson, J. Kutin); Belgium: Antwerp South/Antwerp Central (P. Vermeire, F. van Bastelaer); Estonia: Tartu (R. Jõgi); France: Bordeaux (A. Taytard), Grenoble (I. Pin, C. Pison), Paris (F. Neukirch, R. Liard), Montpellier ( J. Bousquet, J. Knani); Germany: Erfurt (H-E. Wichmann, J. Heinrich), Hamburg (H. Magnussen, D. Nowak); Iceland: Reykjavik (T. Gislason, D. Gislason); Italy: Pavia (A. Marinoni, I. Cerveri), Turin (M. Bugiani, C. Bucca, C. Romano), Verona (R. de Marco ${ }^{\dagger}$, L. Cascio, C. Campello); the Netherlands: Groningen (J. Droste, M. Kerkhof); Norway: Bergen (A. Gulsvik, E. Omenaas); Spain: Albacete (J. Martinez-Moratalla, E. Almar, A. Mateos, M. Arévalo, A. Sánchez, M. Vizcaya, X. Aguilar, A. Teixidó), Barcelona (J.M. Antó, M. Kogevinas, J. Sunyer, F. Burgos, J. Castellsagué, J. Roca, JB. Soriano, A. Tobías), Galdakao (N. Muiñozguren, J. Ramos González, A. Capelastegui), Huelva (J. Maldonado Pérez, A. Pereira, J. Sánchez), Oviedo (J. Quiros, I. Huerta, F. Payo); Sweden: Gothenburg (N. Lindholm, P. Plaschke), Uppsala (G. Boman, C. Janson, E. Björnsson), Umeå (L. Rosenhall, E. Norrman, B. Lundbäck); Switzerland: Basel (U. Ackermann-Liebrich, N. Küenzli, A. Perruchoud); UK: Caerphilly (M. Burr ${ }^{\dagger}$, J. Layzell), Ipswich (R. Hall), Norwich (B. Harrison).

The members of the ECRHS II scientific team. Coordinating Centre (London): P. Burney, S. Chinn, C. Luczynska ${ }^{\dagger}$, D. Jarvis, J. Knox. Project Management Group: P. Burney (Project Leader; UK), S. Chinn (UK), C. Luczynska ${ }^{\dagger}$ (UK), D. Jarvis (UK), P. Vermeire (Antwerp), J. Bousquet (Montpellier), J. Heinrich (Erfurt), M. Wjst (Munich), R. de $\mathrm{Marco}^{\dagger}$ (Verona), J.M. Anto (Barcelona), J. Sunyer (Barcelona), C. Janson (Uppsala), U. Ackermann-Liebrich (Basel), N. Kuenzli (University of Basel and University of Southern California, LA, USA), F. Neukirch (Paris). Participating Centres: Australia: Melbourne (M. Abramson, E.H. Walters, J. Raven); Belgium: Antwerp South/Antwerp Central (P. Vermeire, J. Weyler, M. van Sprundel, V. Nelen); Estonia: Tartu (R. Jõgi, A. Soon); France: Bordeaux (A. Taytard, C. Raherison), Grenoble (I. Pin, J. Ferran-Quentin), Paris (F. Neukirch, B. Leynaert, R. Liard, M. Zureik), Montpellier ( J. Bousquet, P.J. Bousquet); Germany: Erfurt (J. Heinrich, M. Wjst, C. Frye, I. Meyer), Hamburg (H. Magnussen, D. Nowak); Iceland: Reykjavik (T. Gislason, E. Bjornsson, D. Gislason, K.B. Jörundsdóttir); Italy: Pavia (A. Marinoni, S. Villani, M. Ponzio, F. Frigerio, M. Comelli, M. Grassi, I. Cerveri, A. Corsico), Turin (R. Bono, M. Bugiani, P. Piccioni, E. Caria, A. Carosso, E. Migliore, G. Castiglioni), Verona (R. de Marco ${ }^{\dagger}$, G. Verlato, E. Zanolin, S. Accordini, A. Poli, 
V. Lo Cascio, M. Ferrari, I. Cazzoletti); the Netherlands: Groningen (M. Kerkhof); Norway: Bergen (A. Gulsvik, E. Omenaas, C. Svanes, B. Laerum); Spain: Albacete (J. Martinez-Moratalla Rovira, E. Almar, M. Arévalo, C. Boix, G. González, J.M. Ignacio García, J. Solera, J. Damián), Barcelona (J.M. Antó, J. Sunyer, M. Kogevinas, J.P. Zock, X. Basagaña, A. Jaen, F. Burgos, C. Acosta), Galdakao (N. Muñozguren, J. Ramos, I. Urrutia, U. Aguirre), Huelva ( J. Maldonado, A. Pereira, J.L. Sanchez), Oviedo (F. Payo, I. Huerta, A. de la Vega, L. Palenciano, J. Azofra, A. Cañada); Sweden: Gothenburg (K. Toren, L. Lillienberg, A.C. Olin, B. Balder, A. Pfeifer-Nilsson, R. Sundberg), Uppsala (C Janson, G. Boman, D. Norback, G. Wieslander, M. Gunnbjornsdottir), Umeå (E. Norrman, M. Soderberg, K.A. Franklin, B. Lundback, B. Forsberg, L. Nystrom); Switzerland: Basel (N. Küenzli, B. Dibbert, M. Hazenkamp, M. Brutsche, U. Ackermann-Liebrich); UK: Caerphilly (M. Burr ${ }^{\dagger}$, J. Layzell), Ipswich (D. Jarvis, R. Hall, D. Seaton), Norwich (D. Jarvis, B. Harrison).

The members of the ECRHS III scientific team. Coordinating Centre (London): D. Jarvis, P. Burney, M. Tumilty, J. Potts. Project Management Group: D. Jarvis (UK), P. Burney (UK), J. Heinrich (Erfurt), R. de Marco ${ }^{\dagger}$ (Verona), J.M. Anto (Barcelona), C. Janson (Uppsala), K. Toren (Gothenburg), T. Gislasson (Iceland), T. Rochat (Basel), B. Leyneart (Paris), C. Svanes (Bergen), J. Weyler (Antwerp), J.P. Zock (Barcelona). Participating Centres: Australia: Melbourne (M. Abramson, G. Benke, S. Dharmage, B. Thompson, S. Kaushik, M. Matheson); Belgium: South Antwerp/Antwerp City (J. Weyler, H. Bentouhami, V. Nelen); Estonia: Tartu (R. Jõgi, H. Orru); France: Bordeaux (C. Raherison, P.O. Girodet), Grenoble (I. Pin, V. Siroux, J. Ferran, J.L. Cracowski), Montpellier (P. Demoly, A. Bourdin, I. Vachier), Paris (B. Leynaert, D. Soussan, D. Courbon, C. Neukirch, L. Alavoine, X. Duval, I. Poirier); Germany: Erfurt (J. Heinrich, E. Becker, G. Woelke, O. Manuwald), Hamburg (H. Magnussen, D. Nowak, A-M. Kirsten); Iceland: Reykjavik (T. Gislason, B. Benediktsdottir, D. Gislason, E.S. Arnardottir, M. Clausen, G. Gudmundsson, L. Gudmundsdottir H. Palsdottir, K. Olafsdottir, S. Sigmundsdottir, K. Bara-Jörundsdottir); Italy: Pavia (I. Cerveri, A. Corsico, A. Grosso, F. Albicini, E. Gini, E.M. Di Vincenzo, V. Ronzoni, S. Villani, F. Campanella, M. Gnesi, F. Manzoni, L. Rossi, O. Ferraro), Turin (M. Bugiani, R. Bono, P. Piccioni, R. Tassinari, V. Bellisario, G. Trucco), Verona (R. de Marco ${ }^{\dagger}$, S. Accordini, L. Calciano, L. Cazzoletti, M. Ferrari, A.M. Fratta Pasini, F. Locatelli, P. Marchetti, A. Marcon, E. Montoli, G. Nguyen, M. Olivieri, C. Papadopoulou, C. Posenato, G. Pesce, P. Vallerio, G. Verlato, E. Zanolin); the Netherlands: Groningen (H.M. Boezen); Norway: Bergen (C. Svanes, E. Omenaas, A. Johannessen, T. Skorge, F. Gomez Real); Spain: Albacete (J. Martinez-Moratalla Rovira, E. Almar, A. Mateos, S. García, A. Núñez, P. López, R. Sánchez, E. Mancebo), Barcelona (J-M. Antó, J.P. Zock, J. Garcia-Aymerich, M. Kogevinas, X. Basagaña, A.E. Carsin, F. Burgos, C. Sanjuas, S. Guerra, B. Jacquemin, P. Davdand Galdakao: N. Muñozguren, I. Urrutia, U. Aguirre, S. Pascual), Huelva ( J. Antonio Maldonado, A. Pereira, J.L. Sánchez, L. Palacios), Oviedo (F. Payo, I. Huerta, N. Sánchez, M. Fernández, B. Robles); Sweden: Gothenburg (K. Torén, M. Holm, J-L. Kim, A-C. Olin, A. Dahlman-Höglund), Umeå (B. Forsberg, L. Braback, L. Modig, B. Järvholm, H. Bertilsson, K.A. Franklin, C. Wahlgreen), Uppsala (B. Andersson, D. Norback, U. Spetz Nystrom, G. Wieslander, G.M. Bodinaa Lund, K. Nisser); Switzerland: Basel (N.M. Probst-Hensch, N. Künzli, D. Stolz, C. Schindler, T. Rochat, J.M. Gaspoz, E. Zemp Stutz, M. Adam, C. Autenrieth, I. Curjuric, J. Dratva, A. Di Pasquale, R. Ducret-Stich, E. Fischer, L. Grize, A. Hensel, D. Keidel, A. Kumar, M. Imboden, N. Maire, A. Mehta, H. Phuleria, M. Ragettli, M. Ritter, E. Schaffner, G.A. Thun, A. Ineichen, T. Schikowski, M. Tarantino, M. Tsai); UK: London (P. Burney, D. Jarvis, S. Kapur, R. Newson, J. Potts), Ipswich (D. Jarvis, M. Tumilty, N. Innes), Norwich (D. Jarvis, M. Tumilty, A. Wilson)

Conflict of interest: J.A. Gullón has nothing to disclose. R. Jogi reports receiving Estonian Research Council Personal Research Grant 562 during the conduct of the study; consultancy and lecture fees from GSK, Boehringer and Novartis, and travel, accommodation and meeting expenses from GSK and Boehringer. A. Johannessen has nothing to disclose. V. Bellisario has nothing to disclose. C. Janson reports receiving personal fees for lectures and advisory boards from AstraZeneca, Boehringer Ingelheim, Chiesi, Novartis and Teva, and for advisory boards from GSK, outside the submitted work. D. Jarvis reports receiving grants from Medical Research Council, during the conduct of the study. D. Gislason has nothing to disclose. I. Pin reports receiving travel grants from MSD, presentation fees from Teva, and both from AstraZeneca, outside the submitted work. J.L. Sánchez-Ramos has nothing to disclose. Isa Cerveri has nothing to disclose. S. Accordini has nothing to disclose. J.J. Weyler has nothing to disclose. R. Nielsen reports receiving grants from Boehringer Ingelheim and Novartis, personal fees from AstraZeneca, and grants and personal fees from GSK, outside the submitted work. L. Cazzoletti has nothing to disclose. J. Garcia-Aymerich has nothing to disclose. M. Holm has nothing to disclose. J. Martinez-Moratalla Rovira has nothing to disclose. V. Siroux reports receiving speakers' honoraria from AstraZeneca, Novartis and Teva, outside the submitted work. A. Corsico has nothing to disclose. A. Marcon has nothing to disclose. S. Chanoine reports personal fees for board membership from AstraZeneca, and travel, accommodation and meeting expenses from Boehringer Ingelheim, Actelion Pharmaceuticals and MSD, outside the submitted work. J. Quint reports receiving grants from The Health Foundation, the MRC, the British Lung Foundation and IQVIA, grants and advisory board fees from GSK, Boehringer Ingelheim and AstraZeneca, travel fees from Chiesi and Teva, grants and speaking fees from Insmed, grants and consultancy fees from Bayer, outside the submitted work. D.S. Ferreira reports receiving grants from the Asthma Foundation of Victoria, Allen and Hanburys, and the National Health and Medical Research Council during the conduct of the study. D. Nowak has nothing to disclose. A. Malinovschi has nothing to disclose. K.A. Franklin has nothing to disclose. J. Heinrich has nothing to disclose.

Support statement: The coordination of ECRHS I was supported by the European Commission. The following grants helped to fund the local studies. Australia: Asthma Foundation of Victoria, Allen and Hanburys. Belgium: Belgian Science Policy Office, National Fund for Scientific Research. Denmark: Aarhus (R. Dahl, M. Iversen). Estonia: Estonian Science Foundation (1088). France: Ministère de la Santé, Glaxo France, Insitut Pneumologique d'Aquitaine, Contrat de Plan Etat-Région Languedoc-Rousillon, CNMATS, CNMRT (90MR/10 and 91AF/6), Ministre delegué de la santé, RNSP, France, GSF. Germany: Bundesminister für Forschung und Technologie. Greece: The Greek Secretary General of Research and Technology, Fisons, Astra and Boehringer Ingelheim. Italy: Ministero dell'Università e della Ricerca Scientifica e Tecnologica, CNR, Regione Veneto (RSF 381/05.93). The Netherlands: Dutch Ministry of Wellbeing, Public Health and Culture and the Netherlands Asthma Foundation. Norway: Norwegian Research Council project 101422/310. Portugal: Glaxo Farmacêutica Lda, Sandoz Portugesa. Spain: Fondo de Investigación Sanitaria (91/0016-060-05/E, 92/ 0319 and 93/0393), Hospital General de Albacete, Hospital General Juan Ramón Jiménez, Dirección Regional de Salud 
Pública (Consejería de Sanidad del Principado de Asturias), CIRIT (1997 SGR 00079) and Servicio Andaluz de Salud. Sweden: Swedish Medical Research Council, Swedish Heart Lung Foundation, Swedish Association against Asthma and Allergy. Switzerland: Swiss National Science Foundation (4026-28099). UK: National Asthma Campaign, British Lung Foundation, Dept of Health, South Thames Regional Health Authority.

The coordination of ECRHS II was supported by the European Commission. The following grants helped to fund the local studies. Australia: National Health and Medical Research Council. Belgium: Antwerp: Fund for Scientific Research (G.0402.00), University of Antwerp, Flemish Health Ministry. Estonia: Tartu Estonian Science Foundation (4350). France: all: Programme Hospitalier de Recherche Clinique-Direction de la Recherche Clinique (DRC) de Grenoble 2000 number 2610, Ministry of Health, Ministère de l'Emploi et de la Solidarité, Direction Génerale de la Santé, CHU de Grenoble; Bordeaux: Institut Pneumologique d'Aquitaine; Grenoble: Comite des Maladies Respiratoires de l'Isere; Montpellier: Aventis (France), Direction Regionale des Affaires Sanitaires et Sociales Languedoc-Roussillon; Paris: Union Chimique Belge-Pharma (France), Aventis (France), Glaxo France. Germany: Erfurt: GSF-National Research Centre for Environment and Health, Deutsche Forschungsgemeinschaft (FR1526/1-1); Hamburg: GSF-National Research Centre for Environment and Health, Deutsche Forschungsgemeinschaft (MA 711/4-1). Iceland: Icelandic Research Council, Icelandic University Hospital Fund; Italy: Pavia: GSK Italy, Italian Ministry of University and Scientific and Technological Research (MURST), Local University Funding for Research 1998 and 1999; Turin: Azienda Sanitaria Locale 4 Regione Piemonte (Italy), Azienda Ospedaliera Centro Traumatologico Ospedaliero/Centro Traumatologico Ortopedico-Istituto Clinico Ortopedico Regina Maria Adelaide Regione Piemonte; Verona: Ministero dell'Universitá e della Ricerca Scientifica (MURST), Glaxo Wellcome SpA. Norway: Bergen: Norwegian Research Council, Norwegian Asthma and Allergy Association, Glaxo Wellcome AS, Norway Research Fund. Spain: Fondo de Investigacion Santarias (97/0035-01, 99/0034-01 and 99/0034 02), Hospital Universitario de Albacete, Consejeria de Sanidad; Barcelona: Sociedad Espanola de Neumología y Cirugía Toracica, Public Health Service (R01 HL62633-01), Fondo de Investigaciones Santarias (97/0035-01, 99/0034-01 and 99/0034-02), Consell Interdepartamental de Recerca i Innovació Tecnològica (1999SGR 00241) Instituto de Salud Carlos III: Red de Centros de Epidemiología y Salud Pública (C03/09), Red de Bases moleculares y fisiológicas de las Enfermedades Respiratorias (C03/011) and Red de Grupos Infancia y Medio Ambiente (G03/176); Huelva: Fondo de Investigaciones Santarias (97/0035-01, 99/0034-01 and 99/0034-02); Galdakao: Basque Health Dept Oviedo: Fondo de Investigaciones Sanitaria (97/0035-02, 97/0035, 99/0034-01, 99/ 0034-02, 99/0034-04, 99/0034-06, 99/350 and 99/0034-07), European Commission (EU-PEAL PL01237), Generalitat de Catalunya (CIRIT 1999 SGR 00214), Hospital Universitario de Albacete, Sociedad Española de Neumología y Cirugía Torácica (SEPAR R01 HL62633-01) Red de Centros de Epidemiología y Salud Pública (C03/09), Red de Bases moleculares y fisiológicas de las Enfermedades Respiratorias (C03/011) and Red de Grupos Infancia y Medio Ambiente (G03/176) (97/0035-01, 99/0034-01 and 99/0034-02). Sweden: Swedish Heart Lung Foundation, Swedish Foundation for Health Care Sciences and Allergy Research, Swedish Asthma and Allergy Foundation, Swedish Cancer and Allergy Foundation, Swedish Council for Working Life and Social Research (FAS). Switzerland: Swiss National Science Foundation, Swiss Federal Office for Education and Science, Swiss National Accident Insurance Fund. UK: Asthma UK (formerly known as National Asthma Campaign).

The coordination of ECRHS III was supported by the Medical Research Council (92091). The following grants helped to fund the local studies. Australia: National Health and Medical Research Council. Belgium: Research Foundation Flanders (FWO; .0.410.08.N.10) (both sites). Estonia: Tartu: SF0180060s09 from the Estonian Ministry of Education. France: all: Ministère de la Santé. Programme Hospitalier de Recherche Clinique (PHRC) national 2010; Bordeaux: INSERM U897 Université Bordeaux segalen; Grenoble: Comite Scientifique AGIRadom 2011; Paris: Agence Nationale de la Santé, Région Ile de France, domaine d'intérêt majeur (DIM). Germany: Erfurt: German Research Foundation (HE 3294/10-1); Hamburg: German Research Foundation (MA 711/6-1 and NO 262/7-1). Iceland: The Landspitali University Hospital Research Fund, University of Iceland Research Fund, ResMed Foundation (CA, USA), Orkuveita Reykjavikur (Geothermal Plant), Vegagerðin (The Icelandic Road Administration). Italy: all: Italian Ministry of Health, Chiesi Farmaceutici SpA; Verona: funded by Cariverona Foundation, Education Ministry (MIUR). Norway: Norwegian Research Council (214123), Western Norway Regional Health Authorities (911631), Bergen Medical Research Foundation. Spain: Fondo de Investigación Sanitaria (PS09/02457, PS09/00716 09/01511, PS09/02185 and PS09/03190), Servicio Andaluz de Salud, Sociedad Española de Neumología y Cirurgía Torácica (SEPAR 1001/2010), Fondo de Investigación Sanitaria (PS09/02457); Barcelona: Fondo de Investigación Sanitaria (PS09/00716); Galdakao: Fondo de Investigación Sanitaria (09/01511); Huelva: Fondo de Investigación Sanitaria (PS09/02185) and Servicio Andaluz de Salud; Oviedo: Fondo de Investigación Sanitaria (PS09/03190). Sweden: Swedish Heart and Lung Foundation, Swedish Asthma and Allergy Association, Swedish Association against Lung and Heart Disease, Swedish Research Council for Health, Working Life and Welfare (FORTE); Gothenburg: further funding from the Swedish Council for Working Life and Social Research; Umeå: Vasterbotten Country Council ALF grant. Switzerland: Swiss National Science Foundation (33CSCO-134276/1, 33CSCO-108796, 3247BO-104283, 3247BO-104288, 3247BO-104284, 3247-065896, 3100-059302, 3200-052720, 3200-042532 and 4026-028099), The Federal Office for Forest, Environment and Landscape, The Federal Office of Public Health, The Federal Office of Roads and Transport, the Canton's Government of Aargan, Basel-Stadt, Basel-Land, Geneva, Luzern, Ticino, Valais and Zürich, the Swiss Lung League, the Canton's Lung League of Basel-Stadt/Basel, Landschaft, Geneva, Ticino, Valais and Zurich, SUVA, Freiwillige Akademische Gesellschaft, UBS Wealth Foundation, Talecris Biotherapeutics GmbH, Abbott Diagnostics, European Commission 018996 (GABRIEL), Wellcome Trust (WT 084703MA). UK: Medical Research Council (92091); support also provided by the National Institute for Health Research through the Primary Care Research Network.

\section{References}

1 Global Initiative for Asthma. Global Strategy for Asthma Management and Prevention. 2018. http://ginasthma.org/ 2018-gina-report-global-strategy-for-asthma-management-and-prevention Date last accessed: April 11, 2018.

2 Ställberg B, Lisspers K, Hasselgren M, et al. Asthma control in primary care in Sweden: a comparison between 2001 and 2005. Prim Car Respir J 2009; 18: 279-286.

3 Cazzoletti L, Marcon A, Janson C, et al. Asthma control in Europe: a real-world evaluation based on an international population-based study. J Allergy Clin Immunol 2007; 120: 1360-1367. 
4 Rabe KF, Vermeire PA, Soriano JB, et al. Clinical management of asthma in 1999: the Asthma Insights and Reality in Europe (AIRE) study. Eur Respir J 2000; 16: 802-807.

5 Siroux V, Boudier A, Anto JM, et al. Quality-of-life and asthma-severity in general population asthmatics: results of the ECRHS II study. Allergy 2008; 63: 547-554.

6 Ek A, Middelveld R, Bertilsson H, et al. Chronic rhinosinusitis in asthma is a negative predictor of quality of life: results from the Swedish GA2LEN survey. Allergy 2013; 68: 1314-1321.

7 Sundbom F, Lindberg E, Bjerg A, et al. Asthma symptoms and nasal congestion as independent risk factors for insomnia in a general population: results from the GA ${ }^{2}$ LEN survey. Allergy 2013; 68: 213-219.

8 Janson C, De Backer W, Gislason T, et al. Increased prevalence of sleep disturbances and daytime sleepiness in subjects with bronchial asthma: a population study of young adults in three European countries. Eur Respir J 1996; 9: $2132-2138$

9 Accordini S, Corsico A, Cerveri I, et al. The socio-economic burden of asthma is substantial in Europe. Allergy 2007; 63: 116-124

10 Accordini S, Corsico AG, Braggion M, et al. The cost of persistent asthma in Europe: an internationa population-based study in adults. Int Arch Allergy Immunol 2013; 160: 93-101.

11 European Community Respiratory Health Survey. Variations in the prevalence of respiratory symptoms, self-reported asthma attacks, and use of asthma medication in the European Community Respiratory Health Survey (ECRHS). Eur Respir J 1996; 9: 687-695.

12 Janson C, Anto J, Burney P, et al. The European Community Respiratory Health Survey: what are the main results so far? European Community Respiratory Health Survey II. Eur Respir J 2001; 18: 598-611.

13 Janson C, Chinn S, Jarvis D, et al. Physician-diagnosed asthma and drug utilization in the European Community Respiratory Health Survey. Eur Respir J 1997; 10: 1795-1802.

14 Janson C, de Marco R, Accordini S, et al. Changes in the use of anti-asthmatic medication in an international cohort. Eur Respir J 2005; 26: 1047-1055.

15 Janson C, Chinn S, Jarvis D, et al. Individual use of antiasthmatic drugs in the European Community Respiratory Health Survey. Eur Respir J 1998; 12: 557-563.

16 Price D, Fletcher M, van der Molen T. Asthma control and management in 8,000 European patients: the REcognise Asthma and LInk to Symptoms and Experience (REALISE) survey. NPJ Prim Care Respir Med 2014 24: 14009 .

17 Frank PI, Hazell ML, Morris JA, et al. A longitudinal study of changes in respiratory status in young adults 1993-2001. Int J Tuberc Lung Dis 2007; 11: 338-343.

18 Karunanayake CP, Rennie DC, Pahwa P, et al. Predictors of respiratory symptoms in a rural Canadian population a longitudinal study of respiratory health. Can Respir J 2011; 18: 149-153.

19 Schaper C, Glaser S, Obst A, et al. Symptoms and diagnosis of asthma in a general population - longitudina results from the SHIP database. J Asthma 2010; 47: 860-864.

20 Jarvis D, Newson R, Janson C, et al. Prevalence of asthma-like symptoms with ageing. Thorax 2018; 73: 37-48.

21 Burney PG, Luczynska C, Chinn S, et al. The European Community Respiratory Health Survey. Eur Respir J 1994; 7: 954-960.

22 European Community Respiratory Health Survey II Steering Committee. The European Community Respiratory Health Survey II. Eur Respir J 2002; 20: 1071-1079.

23 Fuertes E, Carsin AE, Anto JM, et al. Leisure-time vigorous physical activity is associated with better lung function: the prospective ECRHS study. Thorax 2018; 73: 376-384.

24 British Thoracic Society, Scottish Intercollegiate Guidelines Network. British guideline on the management of asthma revised. 2016. www.brit-thoracic.org.uk/document-library/clinical-information/asthma/btssign-asthmaguideline-2016 Date last accessed: April 11, 2018.

25 Sadatsafavi M, Tavakoli H, Lynd L, et al. Has asthma medication use caught up with the evidence? A 12-year population-based study of trends. Chest 2017; 151: 612-618.

26 Bardal S, Smith A, Luo HA, et al. Asthma in British Columbia: are we finally breathing easier? A population-based study of the burden of disease over 14 years. J Asthma 2017; 54: 308-317.

27 Demoly P, Annunziata K, Gubba E, et al. Repeated cross-sectional survey of patient-reported asthma control in Europe in the past 5 years. Eur Respir Rev 2012; 21: 66-74.

28 Sundh J, Wireklint P, Hasselgren M, et al. Health-related quality of life in asthma patients. A comparison of two cohorts from 2005 and 2015. Respir Med 2017; 132: 154-160.

29 Ducharme FM, Ni Chroinin M, Greenstone I, et al. Addition of long-acting beta ${ }_{2}$-agonists to inhaled corticosteroids versus same dose inhaled corticosteroids for chronic asthma in adults and children. Cochrane Database Syst Rev 2010; 5: CD005535.

30 Rank MA, Liesinger JT, Branda ME, et al. Comparative safety and costs of stepping down asthma medications in patients with controlled asthma. J Allergy Clin Immunol 2016; 137: 1373-1379.

31 Keith PK, Koch C, Djandji M, et al. Montelukast as add-on therapy with inhaled corticosteroids alone or inhaled corticosteroids and long-acting beta-2-agonists in the management of patients diagnosed with asthma and concurrent allergic rhinitis (the RADAR trial). Can Respir J 2009; 16: Suppl. A, 17A-31A.

32 National Institute for Health and Care Excellence. Asthma: tiotropium (Spiriva Respimat). Evidence summary [ESNM55]. 2015. www.nice.org.uk/advice/esnm55/chapter/Key-points-from-the-evidence Date last accessed: April $11,2018$.

33 Haahtela T, Herse F, Karjalainen J, et al. The Finnish experience to save asthma costs by improving care in 1987-2013. J Allergy Clin Immunol 2017; 139: 408-414.

34 Larsson K, Stallberg B, Lisspers K, et al. Prevalence and management of severe asthma in primary care: an observational cohort study in Sweden (PACEHR). Respir Res 2018; 19 : 12.

35 Corsico AG, Cazzoletti L, de Marco R, et al. Factors affecting adherence to asthma treatment in an international cohort of young and middle-aged adults. Respir Med 2007; 101: 1363-1367.

$36 \mathrm{Wu}$ AC, Butler MG, Li L, et al. Primary adherence to controller medications for asthma is poor. Ann Am Thorac Soc 2015; 12: 161-166

37 Laforest L, El Hasnaoui A, Pribil C, et al. Asthma patients' self-reported behaviours toward inhaled corticosteroids. Respir Med 2009; 103: 1366-1375. 